\title{
Intelligent Transportation Systems for Electric Vehicles
}

\author{
Luis B. Elvas ${ }^{1}$ and Joao C Ferreira ${ }^{1,2, *}$
}

Citation: Elvas, L.B.; Ferreira, J.C. Intelligent Transportation Systems for Electric Vehicles. Energies 2021, 14, 5550. https://doi.org/10.3390/ en14175550

Received: 25 August 2021 Accepted: 1 September 2021 Published: 5 September 2021

Publisher's Note: MDPI stays neutral with regard to jurisdictional claims in published maps and institutional affiliations.

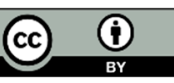

Copyright: $(C) 2021$ by the authors. Licensee MDPI, Basel, Switzerland. This article is an open access article distributed under the terms and conditions of the Creative Commons Attribution (CC BY) license (http://creativecommons.org/licenses/by/4.0/).
1 ISTAR, ISCTE-Instituto Universitário de Lisboa, 1649-026 Lisboa, Portugal; Luis_Manuel_Elvas@iscte-iul.pt

2 Inov Inesc Inovação-Instituto de Novas Tecnologias, 1000-029 Lisbon, Portugal

* Correspondence: joao.carlos.ferreira@iscte-iul.pt

\section{Introduction}

Transportation contributes to more than 25\% of the European Union's (EU) Greenhouse Gas Emissions (GHG) emissions [1]. As such, attaining the European Green Deal's targets would need a significant shift toward cleaner and smarter mobility. Rapid innovation in the electric car industry, on the other hand, appears to be critical to this shift. The Cost of Electric Vehicles (EVs) ownership has decreased in recent years, while viability, measured in terms of range per charge, and acceptance have improved, resulting in an increase in the number of EVs on the road [2]. However, as the industry continues to develop, one market aspect, in particular, requires attention: electric car charging. By the end of 2019, the EU had 195,000 public Electric Vehicle Charging (EVC) sites, or seven electric vehicles per charging point; however, this number will need to rise fast to accommodate the predicted 30 million electric vehicles in Europe's roads by 2030 [3]. It is critical to ensure that EV drivers can readily locate and utilize charging stations while on the road. Additionally, the needed rise in EVCs may have a twofold effect on the energy market. EVs have the potential to significantly strain the energy network, particularly during peak periods, due to the charging requirements provided by EVCs [4]. On the other hand, as these EVs gain smart charging capabilities and battery storage capacity, vehicle to house $(\mathrm{V} 2 \mathrm{H})$ and vehicle to grid (V2G) connectivity may help alleviate some of this strain while also easing the integration of renewable energy sources into the grid [3].

As such, policymakers must implement a well-thought-out strategy that assures adequate coverage of $\mathrm{EV}$ charging stations while also taking into consideration these other critical elements. As a result, the European Commission considers it a priority to examine how access to high-quality EVC can be increased in a user-centric, interoperable, and sustainable manner (with respect to energy system challenges) to fully exploit the potential of EVs for European consumers and companies [3]. This is no simple undertaking given the diverse set of stakeholders (e.g., EV manufacturers, energy DSOs/grid operators, and local government) and the resources necessary across different use cases. Simultaneously, it is clear that EV drivers will require a variety of critical services, including charging, parking, and payment, for which many of these services (e.g., sector convergence, wireless dynamic charging) and associated business models have not been fully defined or, in some cases, discovered. That said, when progress is made, an unknown range of technoeconomic problems may develop.

The key categories for electric vehicle charging points, which are shown via various use scenarios and hint at the significant problems. As a starting point, the following categories are proposed: (1) Operators of Grids; (2) Charging for business, retail, and fleet; (3) Charging on the move; (4) Charging at a residence, a commune, or a housing company.

Grid Operators-EV charging may place strain on the energy system and contribute to grid imbalances, especially if charging occurs during peak hours. On the other side, this might be offset by encouraging and promoting off-peak and bi-directional charging, in which EVs could be charged overnight to help 'smooth the curve,' while remaining 
battery power from the EVs could be supplied back into the home or the grid. Nonetheless, increasing the adoption of electric cars could help lower grid operators' overall carbon impact. Wind farms and photovoltaic (PV) systems convert energy from the wind or sunlight into the electricity required to power the expanding electric mobility sector, which includes commercial, industrial, and residential clients.

Charging for business, retail, and fleet-Charging and parking are critical components of this category, which targets private stakeholders with capacity for private parking management, both B2B and B2C. Charging while parked at work or while engaged in leisure activities such as shopping is an easy method to recharge. From a company perspective, having a charging station on-site will become an increasingly significant amenity for workers, clients, and visitors. Additionally, fleet businesses using electric vehicles will seek a financial framework contract that includes a dependable charging service.

Charging on the move-This category is comparable to the basic infrastructure seen at gasoline stations. Electric fast charging facilities are being created in semi-public locations across cities and roads for drivers who need to refuel their cars throughout their trips. Fast or super-fast chargers with high output ( $50 \mathrm{~kW}$ to $350 \mathrm{~kW}$ ) can charge an electric car in between 10 to $30 \mathrm{~min}$ (https://fastnedcharging.com/hq/everything-youve-alwayswanted-to-know-about-fast-charging/), depending on the battery capacity. Apart from agreeing on applicable fast-charging standards with car OEMs and grid operators, it is up to power providers to dynamically provide energy to superchargers-particularly during holiday seasons and rush hours. Compared to conventional gasoline stations, the on-thego charging stations would require thorough mission planning (including reservation, forecast of usage patterns, and so on) to maintain a minimal level of service.

Charging at a residence, a commune, or a housing company-The charging of the EV close to one's house is essential to this category. Charging at home is frequently the most convenient and cost-effective method of charging for private consumers, as most automobiles are left overnight. Therefore, around $80 \%$ of charging will likely occur at home or work. While regular charging units (up to $22 \mathrm{~kW}$ ) are connected to the central metering unit, they may require extensive power lines/cable infrastructure upgrades, particularly in multi-tenant buildings. In addition, Wall boxes, which are often put on their own circuit for safety and to enable monitoring apart from other electric loads, must be approved to be connected to a smart meter.

The growth of EVs should be accompanied by the development of infrastructure capable of providing charging options for all of them. Electrification is a key potential contributor to shared passenger transportation, with the potential for efficiency gains, cost savings, and carbon emission reductions. This is especially true for last-mile solutions and in metropolitan areas.

Considering these issues, MDPI energy promoted a special issue Intelligent Transportation Systems for Electric Vehicles from the end of 2018 to April 2020 (https://www.mdpi.com/journal/energies/special_issues/Intelligent_Systems_Eletric_Vehicles), accessed in august 2021. A total of 28 papers were submitted from with 15 papers were selected. As a result, in the middle of 2021, a citation score of 89 was reached. Table 1 , shows major papers topics selected from keywords and abstract.

Table 1. MDPI Special Issue main papers highlight.

\begin{tabular}{llc}
\hline Paper & References & \# Documents \\
\hline Review & {$[5]$} & 1 \\
Optimization & {$[5-7]$} & 3 \\
EV & {$[7-18]$} & 12 \\
HEV & {$[5]$} & 1 \\
Urban environment/ & {$[7,10]$} & 2 \\
Urban Transportation & {$[6,8]$} & 2 \\
Intelligent transportation systems & {$[7]$} & 1
\end{tabular}


Energy Management/

Fast Charging

Blockchain

IoT

Electric charging behavior

Energy prices

Computer Vision-object recognition

Artificial Intelligence-Prediction

Mobile APP
[14-17]

$[14,15,17]$

$[11,18]$
3

2

1

2

4

3

1

2

2

From the analyzed papers, paper [5-7] and address optimization problems, wherein [6] the main goal is to achieve a better performance out of the velocity trajectory from the train, being [7] related with electric vehicles, trying to optimize the daily activity chains from travelers in an urban environment and in [5], a review was made concerning the Hybrid Electric Vehicles (HEV) about the Energy Management Strategy (EMS), evaluating both EMS working online and offline, aiming to guide researchers on a better choice.

The authors of the study [8] work on a real case by monitoring an electric bus fleet and analyzing the direct and indirect environmental aspects impacting the emission and health of citizens in Cluj-Napoca, Romania.

Study [9] presents a new paradigm regarding Electric Vehicles (EVs) and the management distribution grids. Concerning Energy management, study [13], addresses the charging requests by considering a battery swap solution, achieving a long-distance trip addressing the challenges of developing appropriate swap battery methods for a large number of EVs with charging demands while also taking into account the variance in the battery charging rate.

Authors of the study [10] intend to save the cost of Urban Complexes (UC), proposing the use of EVs in a UC to reduce the UC's peak power load, allowing lower-capacity power equipment to be employed, lowering the UC's building costs and the transition of electrical facilities.

In the study [11], researchers intend to apply an Internet of Things (IoT) solution to address the charging process in shared spaces by using a set of sensors to measure the energy consumption, using blockchain to handle the financial transition through a mobile app. Concerning the use of mobile apps, researchers on the study [18] make predictions about the availability of a parking slot being free, handling this problem with real-time guidance using collaborative algorithms.

Studies $[12,16]$ lean on fast charging and electric vehicles, where on [12] researchers propose a $1 \mathrm{MW}$ battery charging station to overcome the drawbacks of the use of a normal $480 \mathrm{VAC}$, and in [16], based on IoT, it is suggested an optimal EV rapid charging navigation method.

Addressing problems such as energy prices and electric charging behavior, researchers on [14] study the impact of the energy prices on the users' behavior, and researchers on $[15,17]$ study this impact not only on the user but also on the grid.

Finally, study [19] concerns EVs where the authors develop a sensor fusion algorithm for a forward-collision warning system recurring to neural networks to do object detection. The studies gathered from the MDPI special issue [20] created a graph with the bibliometric networks, as presented in Figure 1, showing the most significant terms extracted from this study. 


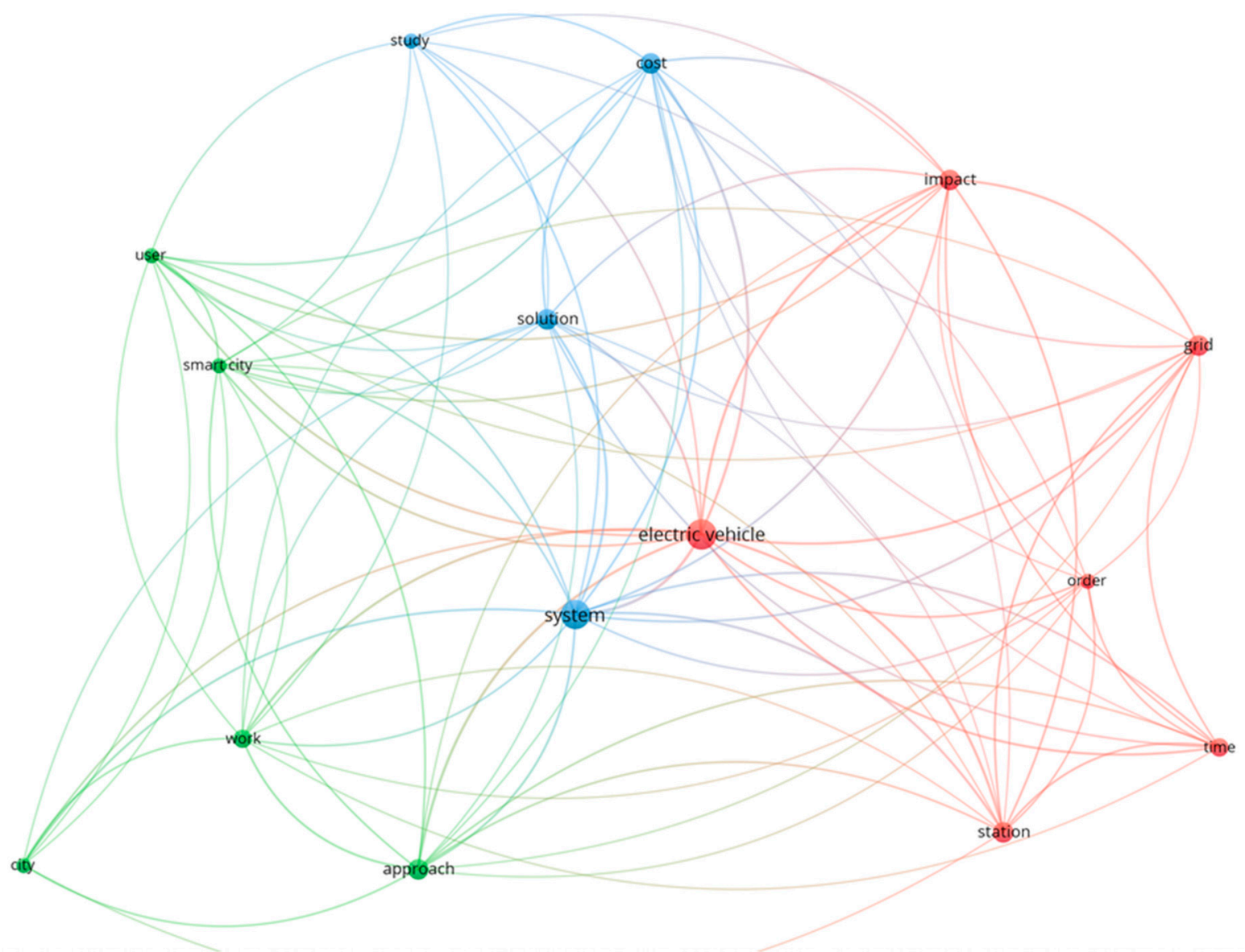

Figure 1. Bag of words relation from abstract and keywords of MDPI special issue [20].

\section{State of the Art}

A systematic literature review was made by following the PRISMA (Preferred Reporting Items for Systematic Reviews and Meta-Analysis) Methodology [21], and with the following research question: "What is the state of the art of Intelligent Transportation Systems on Electric Vehicles?".

Scopus and Web of Science Core Collection (WoSCC) were paper repositories searched, and the research was conducted through August 2021. All the results had to be journal papers, articles, or reviews published between 2019-2021 and written in English.

From our search queries and selection regarding Intelligent Transportation Systems on Electric Vehicles, we found a list of 22 papers with interest to our study, being these papers depicted in Table 2 with its principal contributions.

Table 2. Literature review outputs from last three years using PRISMA methodology.

\begin{tabular}{llc}
\hline Paper & Reference & \# Documents \\
\hline Review & {$[22-26]$} & 5 \\
EV & {$[22,27-39]$} & 14 \\
Plug-in hybrid electric vehicles & {$[23-25,39-43]$} & 7 \\
(PHEVs) & {$[23-25,27,29,34,38,40-43]$} & 11 \\
energy management & {$[22-27,29,31-33,35,37,39-43]$} & 17 \\
intelligent transportation systems & {$[27,41]$} & 2 \\
prediction & {$[30,34-36,38]$} & 5 \\
Optimization & {$[28,33]$} & 2 \\
Fast Charging & {$[31,39]$} & 2 \\
Smart Grid & & 2
\end{tabular}


Concerning reviews, it is noticeable, that most of the works concentrate on PHEVs, where authors [23-25] where the main has been on energy management and intelligent transportation systems, where this topic includes the review $[22,26]$ when it is combined with EVs.

On the topic of PHEVs, we can observe from the studies [40-43] that researchers' main concern is energy management on intelligent transportation systems, with study [41] concerning the prediction of an energy management strategy.

Regarding Energy Management studies [27,29] focus on intelligent transportation systems, where the study [27] differs by the concern of the parking lot management by using a two-stage optimization also predicting the energy prices. Studies [34,38] focus on the optimization of energy on electric vehicles. On the optimization topic, study [36] focuses on the charging costs considering the number of EVs that can be charged simultaneously, while studies $[30,35]$ focus on the consumption of the EVs.

What concerns to Fast Charging, authors of study [28] a customized fast-charging navigation approach is presented, which is based on the mutual impact of dynamic queuing as well as the cost, and authors from study [33] seek to improve the efficiency of EVs in finding a charging station.

Based on the navigation of EV's user studies $[31,32,37]$ present the work on this field, where $[32,37]$ intends to analyze the driving preferences to define a price strategy to divert the traffic flow, meanwhile, study [31] proposes to minimize the travel time and charging cost throw an adaptation to driver preferences recurring to a Deep Reinforcement Learning strategy with the coordinated operation of smart grid. Regarding the Smart Grid's topic, study [39] studies the charging problem of smart-grid charging stations and connected electric vehicles.

By comparing the publications present on Energies and the actual State of the Art, we can notice that the studies of energies aim mainly to Energy management problems in the context of energy prices, optimization on urban environments, energy prices, and the electric charging behavior of the EV's users, while the current state of the art focuses mainly on energy management aiming to charge problems and energy prices, trying also to optimize the EV user's consumption. Figure 2 presents the most important terms used in the literature review from the last three years (2019-2021). When comparing with Figure 1, we can see that on Energies [20] we have 3 main clusters, regarding EVs where it is mainly studying its impact. Its solution is provided to the user in a smart city context, while on the literature review, we have two clusters, where instead of studying the impact of EV, researchers focus is on the time and station, being the other cluster ITS, and its development as well as strategies. 


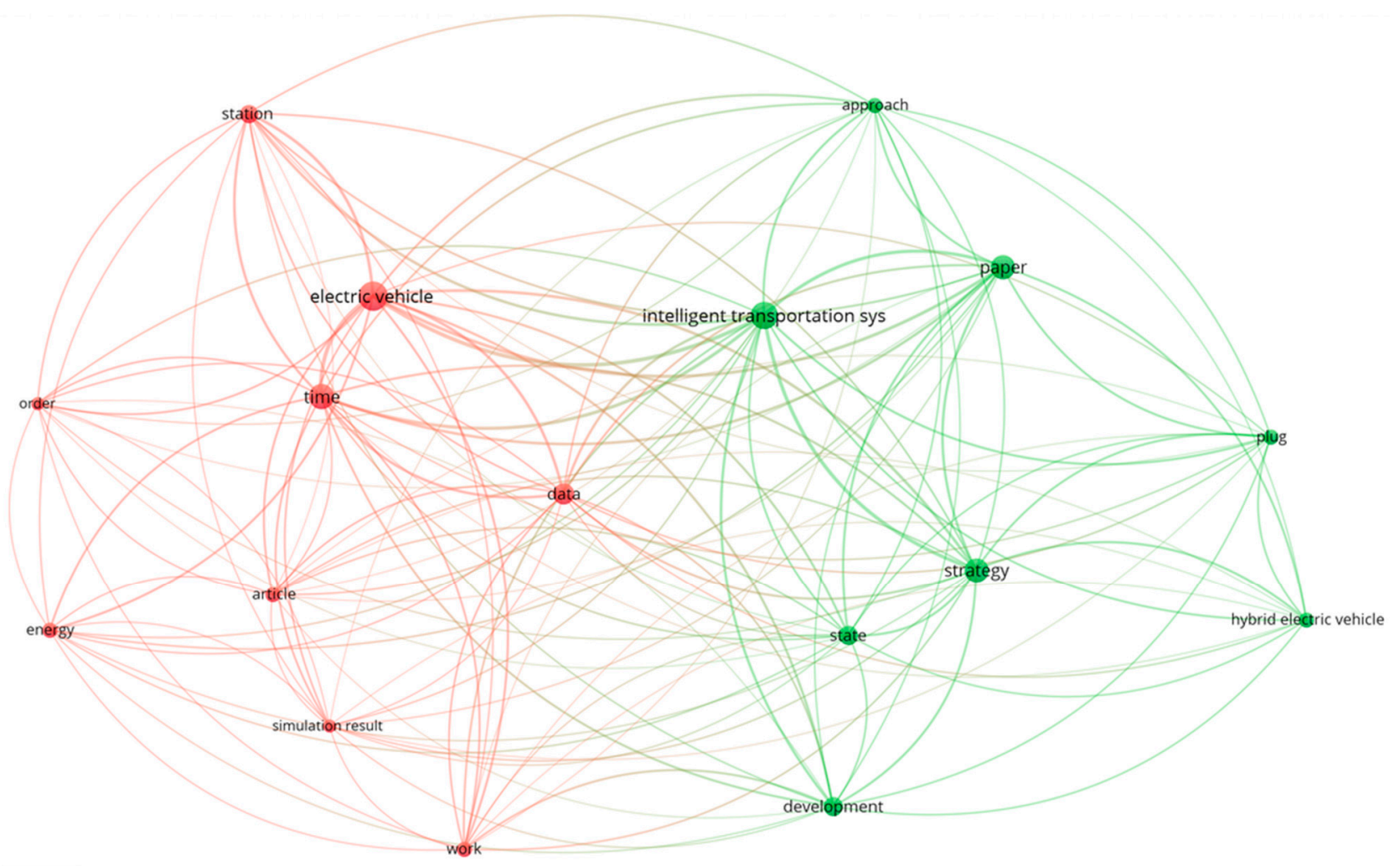

Figure 2. Bag of words from abstracts and keywords of PRISMA systematic literature review.

\section{Smart Energy Management}

EVs major market penetration is the charging process, time of operation, availability of charging spots, and energy operators have to manage power limitations and the introduction of renewable energy sources.

The smart energy management system has emerged as a research topic for future connected car applications. However, significant technological difficulties include the development of decision-making intelligence for the selection of Charging Stations (CSs) and the associated communication infrastructure for information transmission between the power grid and mobile EVs.

The objective of optimum energy management in the context of EV charging is twofold: the first is to optimize the use of renewable energy sources for EV charging; the second is to optimize the whole charging process and the supply of flexible services to the market. Off-peak charging can help prevent peak energy demand surges and enable price optimization, which benefits both customers and grid operators by lowering hourly dayahead wholesale energy market prices.

Charging based on carbon intensity and within the boundaries of existing regional flexibility markets, or contributing to existing regional flexibility markets while increasing flexibility resources. By addressing carbon neutrality effectively through smart energy management, stakeholders may positively contribute to the UN's Sustainable Development Goals 7, 11, and 12.

There is a need to promote smart energy management to customers by grid operators -Manage power limitation taking into account EV owners' energy needs for daily mobility. A diverse engagement of prosumers in service providing to allow clear demand indications from grid operators and market signals are required, and charging in both directions.

Energy management systems (EMS) and bidirectional charging allow EVs to play a complementary role in the energy system, where leftover power may be utilized to power home appliances $(\mathrm{V} 2 \mathrm{H})$ and/or fed back into the grid, contributing to the grid's power balance and developing demand response models [44]. Important achievement topics are 
(1) promotion of bidirectional pricing arrangements with grid operators, businesses such as taxi and retail, big corporations, and consumers; (2) standardization; (3) interoperable solutions; (4) usability; (5) payment methods; (6) user experience in terms of booking, rates (e.g., pay as you go), and charging choices (e.g., fast AC vs. slower DC).

There is a need to stimulate usage (e.g., by strategically placing parking spaces within the business), additional value-added services (e.g., marketing offers), and the shift to a green economy by permitting charging via local renewable energy sources.

Residents without driveways are given precedence. Local governments should collaborate across sectors to examine both hard (integration into the current utility network or roll-out of custom stations) and soft (permits) solutions in public and semi-public areas. Significant takeaways: (1) Raising awareness of the critical nature of addressing this specific use case expeditiously; (2) Establishment of a forum for municipalities; and (3) Investing, business concepts, and legal requirements.

In the case of housing businesses, they wish to serve their residents' EV demands but are now hampered by investment requirements, a confusing business model, and regulatory ambiguity. The shifting market design will affect the evolution of business models and demand response mechanisms. Cross-cutting concerns: (1) Digitization (for example, smart meters, thermostats, and linked charging stations) and data collection are critical to understanding drivers behaviors; (2) Consent to data sharing and data governance continue to be a barrier to new energy services; (3) Establishment of a European Energy Data Space; (4) Ensure that standards for data semantics, security, and trust are visible and repeatable; (5) Standardized data communication protocols and interfaces across actors/sectors are necessary; open access to SMEs and innovators is desirable.

Regulations and zoning regulations-A genuine deployment of electric cars should be encouraged to facilitate the use of infrastructures (common cards to access the charging points, maintenance requirements, etc.). In addition, blockchain and mobile device authentication services can play an important role [45].

\section{Conclusions}

Electric Vehicles' market penetration is increasing, transforming transportation, creating synergies among energy and transportation. From initial blockers, like purchase price, range, charging time, lifetime, and safety are all battery-driven handicaps. In this context smart energy management system plays an important role, where intelligent process plays an important role. This review takes into account the special issue dedicated to this topic at the end of 2018, tries to identify major work performed in the last 3 years, and identifies major topics for the upcoming years.

As attempts to electrify transportation continue, it is critical to conduct a review study about the current status. Intelligence and Technology are enablers for EVs adaptation and play a bridge between transportation and energy. The renewable introduction raises significant challenges, and again, Information System plays an important role. Still, significant work needs to be performed in standardization and regulation. The increasing marketing penetration will raise additional research on intelligent processes to handle energy demand on the charging process while additional infrastructure will be needed. The main goal of this research was to highlight this promising area with the convergence of different knowledge.

Author Contributions: L.B.E. performed the literature review, J.C.F. was responsible for introduction, Smart Energy Management and conclusions. All authors have read and agreed to the published version of the manuscript.

Funding: This research was funded by the Foundation for Science and Technology (FCT) through ISTAR-IUL's project UIDB/04466/2020 and UIDP/04466/2020.

Acknowledgments: J.C.F. received support from the Portuguese National Funds through FITECPrograma Interface, with reference to CIT INOV_INESC INOVAÇÃO-Financiamento Base. 
Conflicts of Interest: The authors declare no conflict of interest.

\section{References}

1. Greenhouse Gas Emissions from Transport in Europe-European Environment Agency. Available online: https://www.eea.europa.eu/data-and-maps/indicators/transport-emissions-of-greenhouse-gases/transport-emissions-ofgreenhouse-gases-12 (accessed on 18 August 2021).

2. Letmathe, P.; Suares, M. A consumer-oriented total cost of ownership model for different vehicle types in Germany. Transp. Res. Part Transp. Environ. 2017, 57, 314-335, doi:10.1016/j.trd.2017.09.007.

3. Electric Vehicles (EV) and Electric Vehicle Charging User Cases Driven Approach/AIOTI. Available online: https://aioti.eu/electric-vehicles-ev-and-electric-vehicle-charging-user-cases-driven-approach/ (accessed 18 August 2021).

4. Moghaddam, V.; Ahmad, I.; Habibi, D.; Phung, Q.V. Smart Charging Strategy for Electric Vehicle Charging Stations. IEEE Trans. Transp. Electrif. 2017, PP, 1, doi:10.1109/TTE.2017.2753403.

5. Zhang, F.; Wang, L.; Coskun, S.; Pang, H.; Cui, Y.; Xi, J. Energy Management Strategies for Hybrid Electric Vehicles: Review, Classification, Comparison, and Outlook. Energies 2020, 13, 3352, doi:10.3390/en13133352.

6. Wang, L.; Wang, X.; Sheng, Z.; Lu, S. Multi-Objective Shark Smell Optimization Algorithm Using Incorporated Composite Angle Cosine for Automatic Train Operation. Energies 2020, 13, 714, doi:10.3390/en13030714.

7. Rizopoulos, D.; Esztergár-Kiss, D. A Method for the Optimization of Daily Activity Chains Including Electric Vehicles. Energies 2020, 13, 906, doi:10.3390/en13040906.

8. Varga, B.O.; Mariasiu, F.; Miclea, C.D.; Szabo, I.; Sirca, A.A.; Nicolae, V. Direct and Indirect Environmental Aspects of an Electric Bus Fleet Under Service. Energies 2020, 13, 336, doi:10.3390/en13020336.

9. Cazzato, F.; Di Clerico, M.; Falvo, M.C.; Ferrero, S.; Vivian, M. New Dispatching Paradigm in Power Systems Including EV Charging Stations and Dispersed Generation: A Real Test Case. Energies 2020, 13, 944, doi:10.3390/en13040944.

10. Xu, Q.; Huang, J.; Han, Y.; Yang, Y.; Luo, L. A Study on Electric Vehicles Participating in the Load Regulation of Urban Complexes. Energies 2020, 13, 2939, doi:10.3390/en13112939.

11. Martins, J.P.; Ferreira, J.C.; Monteiro, V.; Afonso, J.A.; Afonso, J.L. IoT and Blockchain Paradigms for EV Charging System. Energies 2019, 12, 2987, doi:10.3390/en12152987.

12. Liang, Z.; Merced, D.; Jalalpour, M.; Bai, H. Deployment of a Bidirectional MW-Level Electric-Vehicle Extreme Fast Charging Station Enabled by High-Voltage SiC and Intelligent Control. Energies 2020, 13, 1840, doi:10.3390/en13071840.

13. Zhong, L.; Pei, M. Optimal Design for a Shared Swap Charging System Considering the Electric Vehicle Battery Charging Rate. Energies 2020, 13, 1213, doi:10.3390/en13051213.

14. Canizes, B.; Soares, J.; Costa, A.; Pinto, T.; Lezama, F.; Novais, P.; Vale, Z. Electric Vehicles' User Charging Behaviour Simulator for a Smart City. Energies 2019, 12, 1470, doi:10.3390/en12081470.

15. Canizes, B.; Soares, J.; Vale, Z.; Corchado, J. Optimal Distribution Grid Operation Using DLMP-Based Pricing for Electric Vehicle Charging Infrastructure in a Smart City. Energies 2019, 12, 686, doi:10.3390/en12040686.

16. Mo, W.; Yang, C.; Chen, X.; Lin, K.; Duan, S. Optimal Charging Navigation Strategy Design for Rapid Charging Electric Vehicles. Energies 2019, 12, 962, doi:10.3390/en12060962.

17. Monteiro, V.; Afonso, J.; Ferreira, J.; Afonso, J. Vehicle Electrification: New Challenges and Opportunities for Smart Grids. Energies 2018, 12, 118, doi:10.3390/en12010118.

18. Alface, G.; Ferreira, J.C.; Pereira, R. Electric Vehicle Charging Process and Parking Guidance App. Energies 2019, 12, 2123, doi:10.3390/en12112123.

19. Hsu, Y.-W.; Lai, Y.-H.; Zhong, K.-Q.; Yin, T.-K.; Perng, J.-W. Developing an On-Road Object Detection System Using Monovision and Radar Fusion. Energies 2019, 13, 116, doi:10.3390/en13010116.

20. Energies. Available online: https://www.mdpi.com/journal/energies/special_issues/Intelligent_Systems_Electric_Vehicles (accessed on 23 August 2021).

21. Moher, D.; Liberati, A.; Tetzlaff, J.; Altman, D.G. Preferred reporting items for systematic reviews and meta-analyses: the PRISMA statement. BMJ 2009, 339, b2535, doi:10.1136/bmj.b2535.

22. Saharan, S.; Bawa, S.; Kumar, N. Dynamic pricing techniques for Intelligent Transportation System in smart cities: A systematic review. Comput. Commun. 2020, 150, 603-625, doi:10.1016/j.comcom.2019.12.003.

23. Yang, C.; Zha, M.; Wang, W.; Liu, K.; Xiang, C. Efficient energy management strategy for hybrid electric vehicles/plug-in hybrid electric vehicles: Review and recent advances under intelligent transportation system. IET Intell. Transp. Syst. 2020, 14, 702-711, doi:10.1049/iet-its.2019.0606.

24. Wang, P.; Li, J.; Yu, Y.; Xiong, X.; Zhao, S.; Shen, W. Energy management of plug-in hybrid electric vehicle based on trip characteristic prediction. Proc. Inst. Mech. Eng. Part J. Automob. Eng. 2020, 234, 2239-2259, doi:10.1177/0954407020904464.

25. Zhang, F.; Hu, X.; Langari, R.; Cao, D. Energy management strategies of connected HEVs and PHEVs: Recent progress and outlook. Prog. Energy Combust. Sci. 2019, 73, 235-256, doi:10.1016/j.pecs.2019.04.002.

26. Butler, L.; Yigitcanlar, T.; Paz, A. Smart urban mobility innovations: A comprehensive review and evaluation. IEEE Access 2020, 8, 196034-196049, doi:10.1109/ACCESS.2020.3034596. 
27. Sedighizadeh, M.; Mohammadpour, A.; Alavi, S.M.M. A daytime optimal stochastic energy management for EV commercial parking lots by using approximate dynamic programming and hybrid big bang big crunch algorithm. Sustain. Cities Soc. 2019, 45, 486-498, doi:10.1016/j.scs.2018.12.016.

28. Ji, C.; Liu, Y.; Lyu, L.; Li, X.; Liu, C.; Peng, Y.; Xiang, Y. A Personalized Fast-Charging Navigation Strategy Based on Mutual Effect of Dynamic Queuing. IEEE Trans. Ind. Appl. 2020, 56, 5729-5740, doi:10.1109/TIA.2020.2985641.

29. Chaudhary, R.; Jindal, A.; Aujla, G.S.; Aggarwal, S.; Kumar, N.; Choo, K.-K.R. BEST: Blockchain-based secure energy trading in SDN-enabled intelligent transportation system. Comput. Secur. 2019, 85, 288-299, doi:10.1016/j.cose.2019.05.006.

30. Kim, Y.; Figueroa-Santos, M.; Prakash, N.; Baek, S.; Siegel, J.B.; Rizzo, D.M. Co-optimization of speed trajectory and power management for a fuel-cell/battery electric vehicle. Appl. Energy 2020, 260, doi:10.1016/j.apenergy.2019.114254.

31. Qian, T.; Shao, C.; Wang, X.; Shahidehpour, M. Deep Reinforcement Learning for EV Charging Navigation by Coordinating Smart Grid and Intelligent Transportation System. IEEE Trans. Smart Grid 2020, 11, 1714-1723, doi:10.1109/TSG.2019.2942593.

32. Hu, B.; Feng, Y.; Sun, J.; Gao, Y.; Tan, J. Driving preference analysis and electricity pricing strategy comparison for electric vehicles in smart city. Inf. Sci. 2019, 504, 202-220, doi:10.1016/j.ins.2019.07.039.

33. Liu, X. Dynamic response characteristics of fast charging station-evs on interaction of multiple vehicles. IEEE Access 2020, 8 , 42404-42421, doi:10.1109/ACCESS.2020.2977460.

34. Zhang, Y.; Ai, Z.; Chen, J.; You, T.; Du, C.; Deng, L. Energy-Saving Optimization and Control of Autonomous Electric Vehicles With Considering Multiconstraints. IEEE Trans. Cybern. 2021, doi:10.1109/TCYB.2021.3069674.

35. Alturiman, A.; Alsabaan, M. Impact of two-way communication of traffic light signal-to-vehicle on the electric vehicle state of charge. IEEE Access 2019, 7, 8570-8581, doi:10.1109/ACCESS.2018.2890081.

36. Ejaz, W.; Naeem, M.; Sharma, S.K.; Khattak, A.M.; Ramzan, M.R.; Ali, A.; Anpalagan, A. IoV-Based Deployment and Scheduling of Charging Infrastructure in Intelligent Transportation Systems. IEEE Sens. J. 2021, 21, 15504-15514, doi:10.1109/JSEN.2020.3006706.

37. Li, X.; Xiang, Y.; Lyu, L.; Ji, C.; Zhang, Q.; Teng, F.; Liu, Y. Price Incentive-Based Charging Navigation Strategy for Electric Vehicles. IEEE Trans. Ind. Appl. 2020, 56, 5762-5774, doi:10.1109/TIA.2020.2981275.

38. Liu, Q.; He, H. The velocity regulation of power consumption with traffic lights for electric vehicles. Proc. Inst. Mech. Eng. Part J. Automob. Eng. 2019, 233, 2312-2322, doi:10.1177/0954407019856220.

39. Laha, A.; Yin, B.; Cheng, Y.; Cai, L.X.; Wang, Y. Game Theory Based Charging Solution for Networked Electric Vehicles: A Location-Aware Approach. IEEE Trans. Veh. Technol. 2019, 68, 6352-6364, doi:10.1109/TVT.2019.2916475.

40. Taherzadeh, E.; Radmanesh, H.; Mehrizi-Sani, A. A Comprehensive Study of the Parameters Impacting the Fuel Economy of Plug-In Hybrid Electric Vehicles. IEEE Trans. Intell. Veh. 2020, 5, 596-615, doi:10.1109/TIV.2020.2993520.

41. Min, Q.; Li, J.; Liu, B.; Li, J.; Sun, F.; Sun, C. Guided model predictive control for connected vehicles with hybrid energy systems. Energy 2021, 230, doi:10.1016/j.energy.2021.120780.

42. Hu, X.; Zhang, X.; Tang, X.; Lin, X. Model predictive control of hybrid electric vehicles for fuel economy, emission reductions, and inter-vehicle safety in car-following scenarios. Energy 2020, 196, doi:10.1016/j.energy.2020.117101.

43. Zhang, Z.; He, H.; Guo, J.; Han, R. Velocity prediction and profile optimization based real-time energy management strategy for Plug-in hybrid electric buses. Appl. Energy 2020, 280, doi:10.1016/j.apenergy.2020.116001.

44. Monteiro, V.; Exposto, B.; Ferreira, J.C.; Afonso, J.L. Improved Vehicle-to-Home (iV2H) Operation Mode: Experimental Analysis of the Electric Vehicle as Off-Line UPS. IEEE Trans. Smart Grid 2017, 8, 2702-2711, doi:10.1109/TSG.2016.2535337.

45. Ferreira, J.C.; Ferreira da Silva, C.; Martins, J.P. Roaming Service for Electric Vehicle Charging Using Blockchain-Based Digital Identity. Energies 2021, 14, 1686, doi:10.3390/en14061686. 